\title{
POLYMERIC PARTICLE COMPOSITES BASED ON FILLER FROM HEN EGG-SHELLS
}

\author{
Stanislav Petrasek, Miroslav Muller \\ Czech University of Life Sciences in Prague \\ petrasek@tf.czu.cz,muller@tf.czu.cz
}

\begin{abstract}
The paper deals with utilization of a by-product from the food industry, namely waste coming into being at processing hen eggs, i.e. egg-shells. Polymeric particle composites, i.e. structural two-component epoxy resins CHS EPOXY 324 Lepox 1200 filled with microparticles from hen egg-shells of 10, 20, 30 and 40 wt. \% concentrations, were used within the research. The aim of the research was to evaluate the possibilities of the use of the microparticles based on hen egg-shells as the filler in the structural two-component resin. Another aim was to determine the influence of the filler content in the structure of the composite material on the mechanical properties, i.e. the tensile strength, elongation at break and hardness. The tensile strength was increased of $22 \%$ at $10 \mathrm{wt} . \%$ egg-shell microparticle filler. The elongation at break was decreased with increasing the filler weight up of $34.5 \%$. The influence of the filler on the hardness was not statistically proved, however, the filler proved good wettability with the matrix. A scanning electron microscopy MIRA 3 TESCAN (SEM) was used for the description of the created composite material. The research was based on an assumption of an optimization of the waste utilization from renewable resources with the aim to gain a material providing good mechanical properties. The egg-shell microparticle filler proved the effectivity in the area of filling two-component epoxy resin also at high concentrations, i.e. to 40 wt. \%.
\end{abstract}

Keywords: composite, egg-shell microparticles, elongation at break, hardness, tensile strength.

\section{Introduction}

The paper deals with utilization of a by-product from the food industry, namely waste coming into being at processing hen eggs. The production of hen eggs on an industrial level leads to an essential amount of shells, which are regarded as waste or they are used as a supplement in agriculture. Generally, it can be said that the egg-shells are of no economic value [1]. However, they are rich in minerals. This material can be regarded [2] as a source of the calcium filler. Many studies proved their positive influence [1] as an ingredient in various products. It has been demonstrated that using lowcost materials and a relatively simple process complex supports with a mixed inorganic-organic structure can be synthesized [3]. The recent research has been focused on development of biological composites where a matrix or a reinforcement is of a biological essence [4-7]. At present composites containing the biological reinforcement based on waste, i.e. the by-product from the manufacturing industry, [4] have been developed. A natural based material can be defined as a product made from renewable agricultural and forestry feedstock, including crops and crop by-products and their residues [8]. Biocomposites are also made with the use of various other ingredients, e.g., feather, cellulose fibres, coconut, flax, sisal, Ensete ventricosum, seeds of Phoenix, rice - husk, jute etc $[1 ; 5 ; 6 ; 9-14]$.

About several hundred thousand tons of egg-shell waste is produced annually worldwide by the food processing industry only and the utilisation cost of this waste is estimated at millions of euro [1; 15]. Egg-shells represent ca. $11 \%$ of the total mass of eggs [1] and they are available as the waste in huge amounts, namely in food industry. The production of hazelnuts can be regarded as analogous waste. The hazelnut shell is a by-product of the food industry [16]. It is industrial waste, so that it is cost effective and upgrading, it is an interesting challenge. This filler can be grinded to give a lignocellulosic flour that can provide wood-like appearance to polymer composites [16]. It can be used as the reinforcement/filler with a wide variety of polymeric matrices to give wood-like materials that contribute to preserve forestry resources [16]. An optimization of the matrix reinforcing with the filler depends on the interfacial interaction. Transfer of the stress from the matrix to the reinforcement occurs by adhesion, i.e. Coulomb's friction in the interface of the matrix and fibres $[6 ; 17 ; 18]$. There is a logical requirement for the highest strength and creating corresponding mutual interaction [6].

Egg-shell waste is potentially a suitable candidate for an ecological filler material for reinforced biopolymeric composites owing to improving their mechanical properties and the heat stability [1]. Egg-shells contain about $95 \%$ of calcium carbonate (calcite) and $5 \%$ of organic materials such as sulphated polysaccharides, type $X$ collagen and other proteins $[1 ; 15]$. Filling of thermoplastics by calcium carbonate is used in the practice. This filler improves the mechanical properties. This rawmaterial can be substituted by the waste, i.e. the egg-shells. 
The aim of the research was to evaluate the possibilities of the use of the microparticles based on hen egg-shells as the filler in structural two-component resin. Another aim was to determine the influence of the filler content in the structure of the composite material on the mechanical properties, i.e. the tensile strength, elongation at break and hardness. A scanning electron microscopy (SEM) was used for the description of the created composite material. The research was based on an assumption of optimization of the waste utilization from renewable resources with the aim to gain a material providing good mechanical properties.

\section{Materials and methods}

The structural two-component epoxy resin CHS EPOXY 324 Lepox 1200 with the hardener P11 served as the matrix. The following concentrations of the filler were used within the research: 10, 20, 30 and 40 wt. \% of microparticles of egg-shells. Egg-shell waste was obtained from the food industry and subjected to a grinding process. Egg-shells were grinded in an industrial grinder. Fractionalisation was performed on sieves with a mesh size $100 \mu \mathrm{m}$. The particle analysis was performed at the device Haver EML digital plus. The fraction with the smallest particles, i.e. in the interval 0 to $100 \mu \mathrm{m}$ was used for the research. The small particle size aids in a uniform stress transfer between the filler and the matrix, thereby resulting in a composite with superior mechanical performance [15]. The egg-shell microparticles were dried before the application at the temperature $105{ }^{\circ} \mathrm{C}$ for the time $24 \mathrm{~h}$. Zieleniewska et al. state an analogous filler treating process [1].

The test samples for the tensile properties determination (the tensile strength and the elongation at break) according to the standard CSN EN ISO 527-1 (Plastics - Determination of tensile properties Part 1: General principles) were prepared according to the standard CSN EN ISO 3167 (Plastics Multipurpose test specimens, Czech Standard Institution). The test samples were cast into the moulds prepared in advance from a two-component silicone rubber (Lukapren N1522), which corresponded by their shape and dimensions to the requirements of the standard and they were hardened according to the technological requirements of the resin producer (for $48 \pm 0.5$ hours with a temperature $22 \pm$ $\left.2^{\circ} \mathrm{C}\right)$.

The universal tensile strength testing machine LABTest 5.50ST (the Labortech company) was used for the determination of the tensile strength and the elongation at break (Fig. 1 A). The testing machine LABTest 5.50ST is equipped with a sensing unit AST type KAF $50 \mathrm{kN}$ and an evaluating software Test\&Motion is used for the evaluation. The loading speed of the deformation corresponded to $5 \mathrm{~mm} \cdot \mathrm{min}-1$.

The hardness of the composite was measured according to the standard CSN EN ISO 2039 on the device Durajet (the Struers company), Fig. 1 B. The loading force of an intender body (a small ball of the diameter $5 \mathrm{~mm}$ ) was $961 \mathrm{~N}$ (according to requirements of the standard). The intender body was pushed into the surface of the composite material by this loading force. Plastic deformation came into being by this.

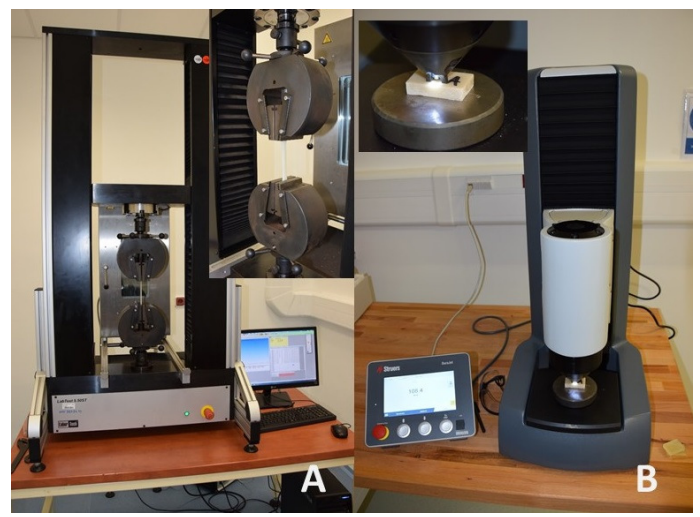

Fig. 1. Measuring of mechanical properties:

A: Tensile test - tensile strength, elongation at break; B: Hardness

Composite materials filled with egg-shell microparticles were analysed by SEM with the aim to evaluate dispersion and fracture surfaces. A microscope MIRA 3 TESCAN at the accelerating voltage 
of the pack (HV) $5.0 \mathrm{kV}$ was used for the research. The samples were dusted with gold by means of the equipment Quorum Q150R ES - Sputtering Deposition Rate.

Statistical hypotheses were also tested at the measured sets of data by means of the program STATISTICA by $F$-test. A validity of the zero hypothesis $\left(H_{0}\right)$ shows that there is no statistically significant difference $(p>0.05)$ among the tested sets of data. On the contrary, the hypothesis $H_{1}$ denies the zero hypothesis and it says that there is a statistically significant difference among the tested sets of data or dependence among variables $(p<0.05)$.

\section{Results and discussion}

It is desirable to integrate renewable resources or waste from crop and livestock production into material engineering $[5 ; 19-21]$. The performed experiment describes the interaction of the egg-shell microparticle filler and epoxy resin. The composite based on local renewable sources comes into being, which excel in their availability and reduced price. Many authors dealt with the use of the secondary products (waste-based) from agricultural crops in their studies and they describe the possibilities to utilize biological-based secondary raw-materials [4-5; 20-21].

Fig. 2 shows the results of the influence of the filler microparticles based on the egg-shells on the tensile strength. The tensile strength was increased in the interval 6.2 to $22 \%$ by adding the egg-shell microparticle filler at the concentrations 10 to $30 \mathrm{wt} . \%$. The significant increase, i.e. $22 \%$ occurred at the concentration $10 \mathrm{wt}$. \%. In terms of the statistical testing of the influence of the egg-shell microparticle concentrations by means of the F-test it is possible to say that the concentrations are statistically non-homogeneous groups $(p=0.0004)$, i.e. there is the difference in the resultant tensile strength among single tested concentrations. The hypothesis $\mathrm{H}_{0}$ was not certified in the significance level 0.05. It is obvious from the results that different concentration influences the tensile strength.

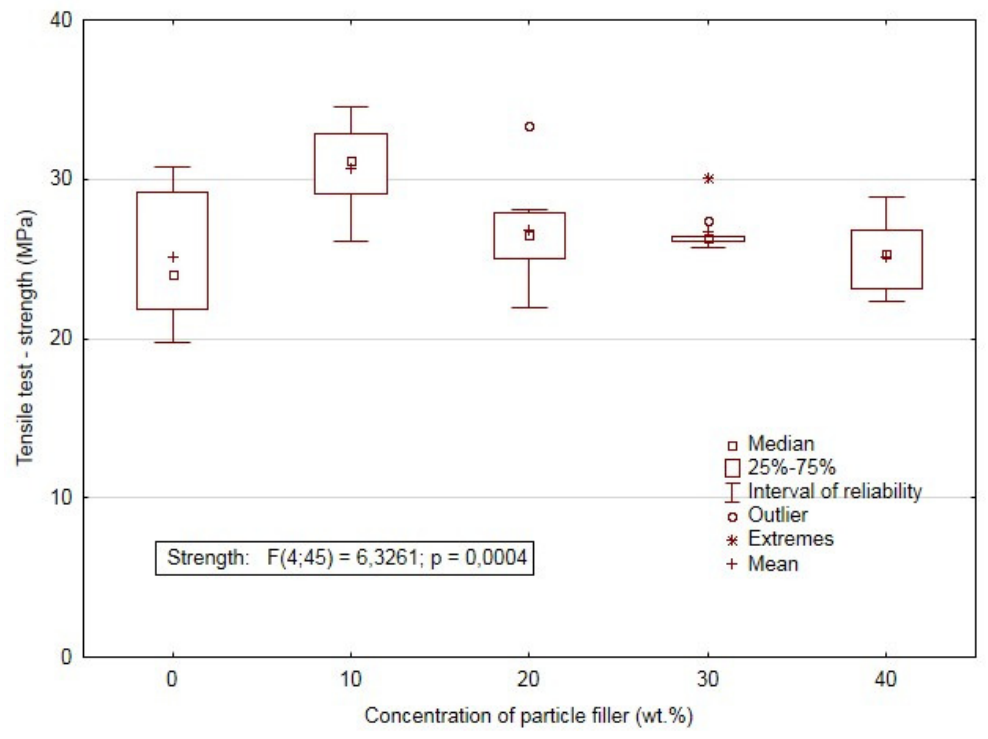

Fig. 2. Influence of concentrations of egg-shell microparticle filler on tensile strength

Fig. 3 shows the results of the influence of the filler microparticles based on the egg-shells on the elongation at break. The elongation at break was decreased by adding the filler microparticles based on the egg-shells at the concentrations 10 to $40 \mathrm{wt}$. \%. The elongation at break declines with increasing the filler weight, namely in the interval from 1.3 to $34.5 \%$.

The hypothesis $H_{0}$ was not certified again in the significance level 0.05 , i.e. the different concentration influences the elongation at break $(p=0.0000)$. The polymeric particle composite based on the egg-shell microparticle filler shows the reduction of the elongation at break. Also Krishman et al. came to the same conclusion [15].

Fig. 4 shows the results of the influence of the filler microparticles based on the egg-shells on the hardness. The hardness was increased in the interval 1 to $5.5 \%$ by adding the egg-shell microparticle filler at the concentrations 10 to $40 \mathrm{wt} . \%$. In terms of the statistical testing of the influence of the eggshell microparticles concentration by means of the F-test it is possible to say that the concentrations 
are statistically homogeneous groups $(p=0.3552)$, i.e. there is no difference in the resultant hardness among single tested concentrations. The hypothesis $H_{0}$ was certified in the significance level 0.05 . It is obvious from the results that different concentrations do not influence the hardness.

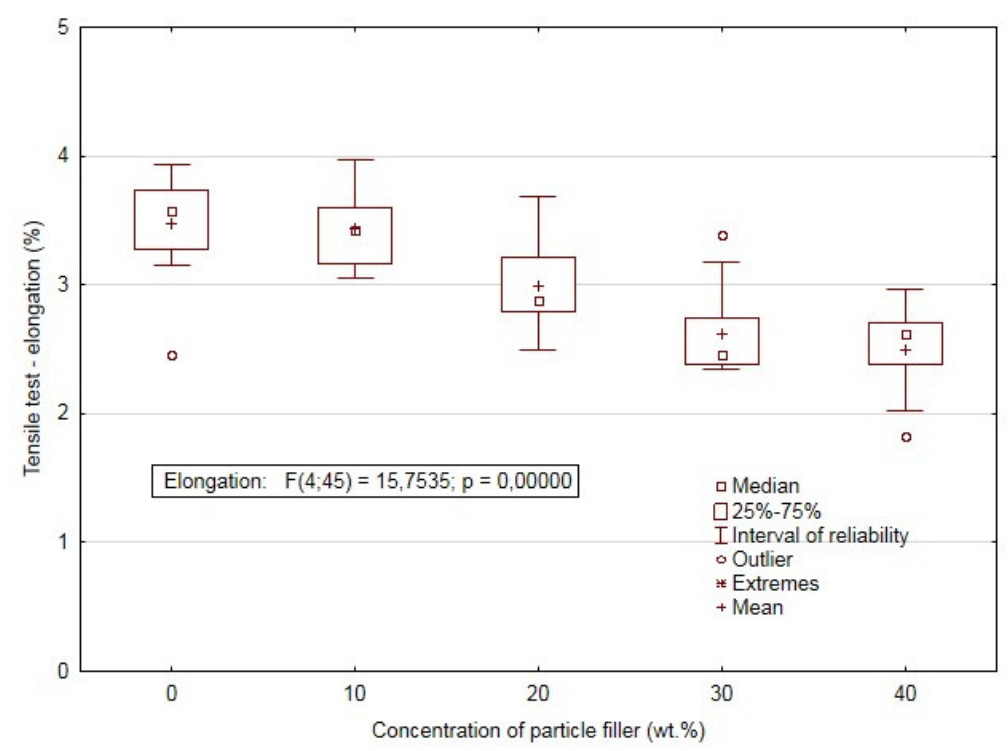

Fig. 3. Influence of concentrations of microparticle filler based on egg shells on elongation at break

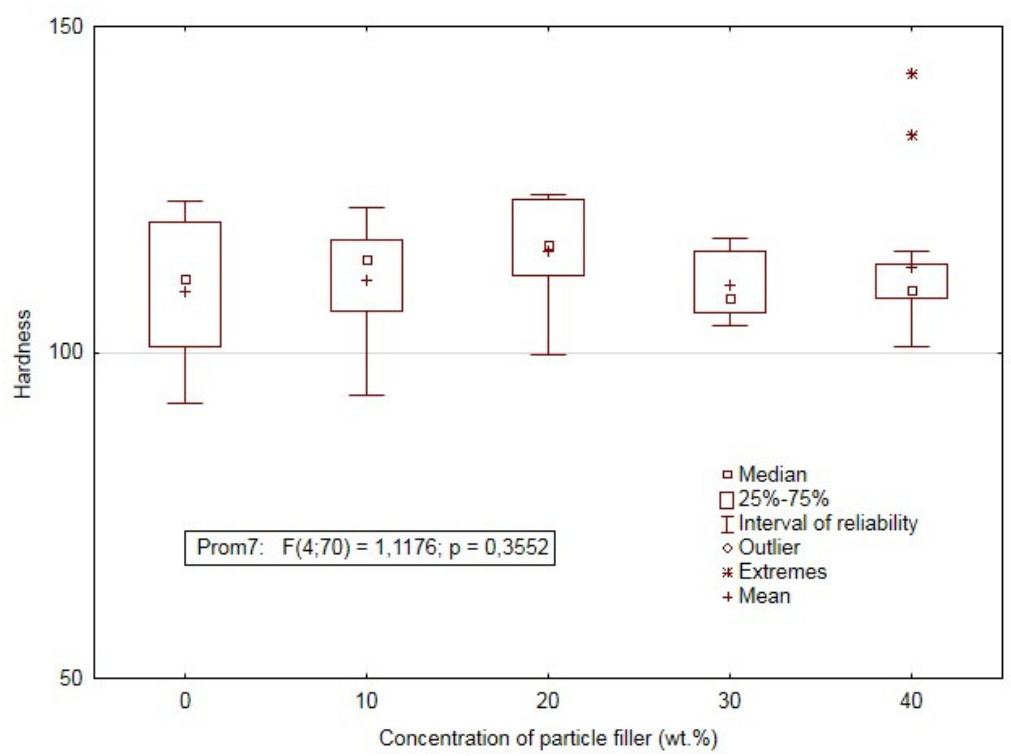

Fig. 4. Influence of concentrations of egg-shell microparticle filler on hardness

The results of the SEM analysis proved the change of the fracture surface after adding already 10 wt. \% of microparticle filler based on the egg shells (Fig. 5 A, B). The fracture surface of the resin without the microparticle filler based on the egg shells showed a regular texture. The fracture surface changed to a coarse-grained texture by adding the microparticle filler based on the egg shells. A detailed view on the interaction between the microparticle filler based on the egg shells and the resin is visible from Fig. 5 C. A destruction of the filler is obvious from Fig. 5 C, i.e. its cohesive strength was smaller than the adhesive strength (adhesion of the resin and the filler).

Bad wettability and non-homogeneity of the natural fillers utilized in the polymeric composites belong among the main disadvantages of their use [20]. The conclusions of various authors were certified that adding the filler into the reactoplastics epoxy-based matrix affected the mechanical properties of the resultant composite $[4-6 ; 22 ; 23]$. A positive effect of the egg-shell microparticle filler in the area of the composite materials is obvious from the research results of Zieleniewska et al. 
[1]. Adding the filler of the concentration 5 to $40 \mathrm{wt}$. \% increased the hardness according to Vickers of the composite material. The same conclusion was certified in our experiments [15].
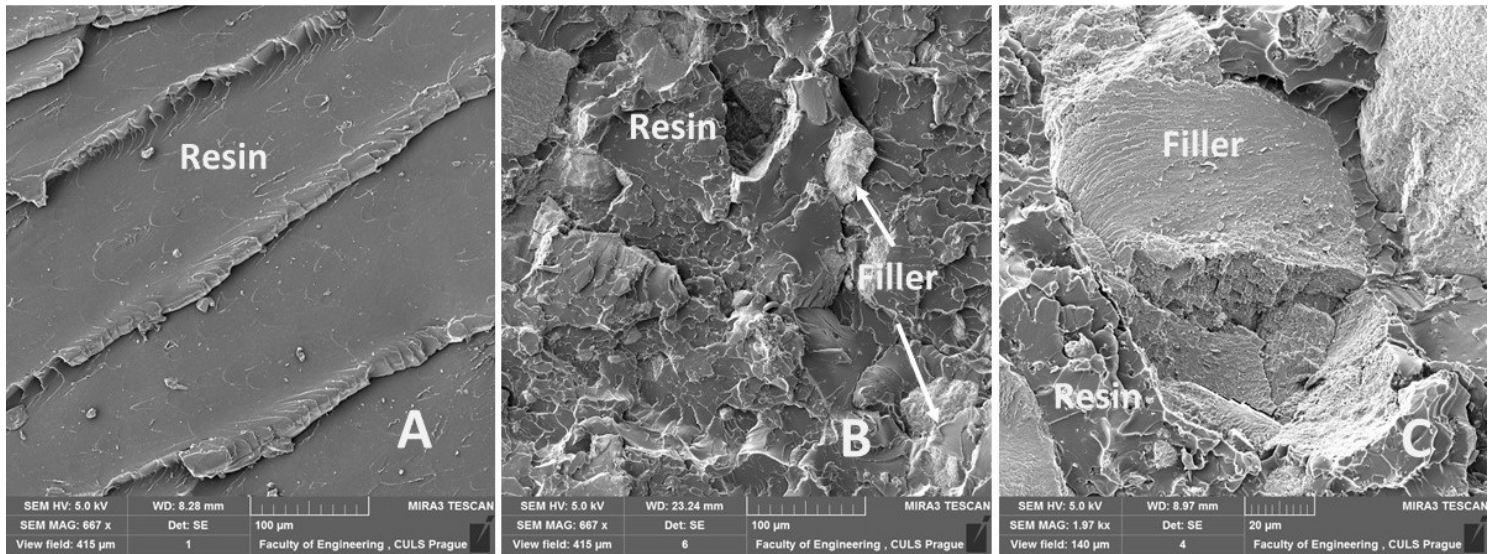

Fig. 5. SEM images of fracture surface after tensile test: A - resin - 0 wt. \% concentration of particle filler (MAG 667 x); B - composite - 10 wt. \% concentration of particle filler (MAG 667 x);

$\mathrm{C}$ - interaction of particle filler and resin (MAG $1.97 \mathrm{kx}$ )

\section{Conclusions}

The following conclusions can be stated from the results of the experiment using the natural filler based on egg-shell microparticles.

1. The tensile strength was increased of $22 \%$ at $10 \mathrm{wt} . \%$ egg-shell microparticle filler. The average tensile strength increase occurred at other concentrations, however, this increase was not statistically significant.

2. The elongation at break was decreased by adding the egg-shell microparticle filler.

3. The influence of the egg-shell microparticle filler on the hardness was not statistically proved.

4. The egg-shell microparticles filler proved good wettability with the matrix, i.e. the resin based on the SEM analysis.

5. The egg-shell microparticle filler proved the effectivity in the area of filling two-component epoxy resin also at high concentrations, i.e. to $40 \mathrm{wt}$ \%.

\section{Acknowledgement}

Supported by Internal grant agency of Faculty of Engineering, Czech University of Life Sciences in Prague (No. 2017:31140/1312/3115).

\section{References}

1. Zieleniewska M., Leszczynski M.K., Szczepkowski L., Bryskiewicz A., Krzyzowska M., Bien K., Ryszkowska J. Development and applicational evaluation of the rigid polyurethane foam composites with egg shell waste. Polymer Degradation and Stability, vol. 132, 2016, pp. 78-86.

2. Oliveira D.A., Benelli P., Amante E.R. A literature review on adding value to solid residues: egg shells. Journal of Cleaner Production, vol. 46, 2013, pp. 42-47.

3. Badanoa J.M., Betti C., Rintoulb I., Vich-Berlanga J., Cagnola E., Torres G., Vera C.,Yori J., Quiroga M. New composite materials as support for selective hydrogenation; egg-shell catalysts. Applied Catalysis A: General 390, 2010, pp. 166-174.

4. Ruggiero A., Valášek P., Müller M. Exploitation of waste date seeds Phoenix dactylifera in form of polymeric particle biocomposite: Investigation on adhesion, cohesion and wear. COMPOSITES PART B-ENGINEERING, vol. 104, 2016, pp. 9-16.

5. Mizera Č., Herák D., Hrabě P., Müller M., Kabutey A. Mechanical Behavior of Ensete ventricosum Fiber Under Tension Loading. Journal of Natural Fibers, vol. 14, No. 2, 2017, pp. 287-296.

6. Müller M., Valášek P., Ruggiero A. Strength characteristics of untreated short-fibre composites from the plant ensete ventricosum. BioResources, vol. 12, No. 1, 2017, pp. 255-269. 
7. Müller M., Valášek P., Rudawska A. Mechanical properties of adhesive bonds reinforced with biological fabric. Journal of Adhesion Science and Technology, 2017, pp. 1-13,

8. Koronis G., Silva A., Fontul M. Green composites. A review of adequate materials for automotive applications. Composites: Part B, vol. 44, 2013, pp. 120-127.

9. Kakou, C.A., Arrakhiz, F.Z., Trokourey, A., Bouhfid, R., Qaiss, A., Rodrigue, D. Influence of coupling agent content on the properties of high density polyethylene composites reinforced with oil palm fibers. Materials and Design, vol. 63, 2014, pp. 641-649.

10. Lu X., Qiu Zhang M., Zhi Rong M., Shi G., Cheng Yang G. Melt processable composites of sisal. Composites Science and Technology, vol. 63, 2003, pp. 177-186.

11. Zhao X., Li R. K.Y., Bai S-L. Mechanical properties of sisal fiber reinforced high density polyethylene composites: Effect of fiber content, interfacial compatibilization, and manufacturing process. Composites: Part A, vol. 65, 2014, pp. 169-174.

12. Doumbia A.S., Castro M., Jouannet D., Kervoëlen A., Falher T., Cauret L., Bourmaud A. Flax/polypropylene composites for lightened structures: Multiscale analysis of process and fibre parameters. Materials and Design, vol. 87, 2015, pp. 331-341.

13. Nasir Abdul A.A., Azmi A.I., Khalil A.N.M. Measurement and optimisation of residual tensile strength and delamination damage of drilled flax fibre reinforced composites. Measurement, vol.75, 2015, pp. 298-307.

14. Ho M.P., Wang H., Lee J.H., Ho C.K., Lau K.T., Leng J., Hui D. Critical factors on manufacturing processes of natural fibre composites. Composites Part B: Engineering, vol. 43, No. 8, 2012, pp. 3549-3562.

15. Cheung H-Y., Ho M-P., Lau K-T. Francisco Cardona, David Hui. Natural fibre-reinforced composites for bioengineering and environmental engineering applications. Composites: Part B, vol. 40, 2009. pp. 655-663.

16. Iyer K.A., Torkelson J.M. Green composites of polypropylene and eggshell: Effective biofiller size reduction and dispersion by single-step processing with solid-state shear pulverization. Composites Science and Technology. Composites Science and Technology, vol. 102, 2014, pp. 152-160.

17. Balart J.F., Fombuena V., Fenollar O., Boronat T., Sanchez-Nacher L. Processing and characterization of high environmental efficiency composites based on PLA and hazelnut shell flour (HSF) with biobased plasticizers derived from epoxidized linseed oil (ELO). Composites Part B, vol. 86, 2016, pp. 168-177.

18. Ruggiero A., Merola M., Carlone P., Archodoulaki V. M. Tribo-mechanical characterization of reinforced epoxy resin under dry and lubricated contact conditions. Composite Part B: Engineering, vol. 79, 2015, pp. 595-603.

19. Hidayat H., Prijanto U., Van Dam J.E.G., Heeres H.J., Keijsers E.R.P. Preparation and properties of binderless boards from Jatropha curcas L. seed cake, Industrial Crops and Products, vol. 52, 2014, pp. 245-254.

20. Badanoa J.M., Betti C., Rintoulb I., Vich-Berlanga J., Cagnola E., Torres G., Vera C., Yori J., Quiroga M. New composite materials as support for selective hydrogenation; egg-shell catalysts, Applied Catalysis A: General, vol. 390, 2010, pp. 166-174.

21. Herrera-Franco PJ, Valadez-Gonzalez A: A study of the mechanical properties of short naturalfiber reinforced composites. Composites: Part B, vol. 36, 2005, pp. 597-608.

22. Kim H.S., Khamis M.A. Fracture and impact behaviours of hollow micro-sphere/epoxy resin composites. In: Composites Part A: Applied Science and Manufacturing, vol. 32, No. 9, 2001, pp. 1311-1317.

23. Agoudlil B., Ibos L., Majesté J.C., Candau Y., Mamunya YE.P. Correlation between transport properties of Ethylene Vinyl Acetate/glass, silver-coated glass spheres composites. In: Composites Part A: Applied Science and Manufacturing, vol. 39, No. 2, 2008, pp. 342-35. 